\title{
A qualitative study to understand the perspectives of MOOC providers on accessibility
}

\author{
Francisco Iniesto, Patrick McAndrew, Shailey Minocha, Tim Coughlan \\ The Open University
}

\begin{abstract}
Massive open online courses (MOOCs) are widely available and have become a common option for learners. However, their full potential cannot be realised if they are not accessible to all learners, including those with disabilities. It is, therefore, important to understand the different stakeholders and their requirements and perspectives in designing accessible MOOCs. This research investigated the perspectives of MOOC providers on MOOC learners who have accessibility needs and the processes used to manage accessibility and MOOCs in their individual organisations. In this paper, we report the results of a study using thematic analysis, which involved 26 semi-structured interviews with MOOC providers and focused on MOOC accessibility. The results show that, while MOOC providers are aware of learners with accessibility needs who are participating in MOOCs, they prioritise legislation over learners' accessibility preferences. MOOC providers consider the technology of the platform itself creates barriers and are aware of the limitations for learners in finding help, reporting accessibility barriers and obtaining feedback, when participating in MOOCs.
\end{abstract}

\section{Implications for policy and practice:}

- Course providers should acknowledge MOOC design is being guided by legal requirements. That involves uncertainty to who is the responsible to deliver accessible MOOCs.

- Platform providers need to consider the lack of information about their learners makes it difficult to design educational resources that consider different target groups and provide personalisation.

- $\quad$ Learners can find MOOCs helpful for continuing professional development and lifelong learning. MOOCs are attractive due to their low-cost and self-regulated learning.

Keywords: accessibility, MOOC, MOOC provider, disability, qualitative research, interview, thematic analysis

\section{Introduction}

The number of students who declare a disability and who use assistive technologies or require adaptations to be able to study in higher education (HE) is increasing every year (Moriña, 2017). A widening participation summary taken from the United Kingdom performance indicators for 2020 shows that the participation of students with declared disabilities in HE in 2020 was $7 \%$, having increased from $4.5 \%$ in 2008 and 1.5\% in 2001 (Higher Education Statistics Agency, 2021). Coughlan et al. (2016) noted that there is an increase of students who declare a disability on average across HE institutions, with increases particularly in distance universities, which may reflect the higher flexibility that online and distance education offer for students who declare a disability.

For example, The Open University (2019) reported 27,237 enrolled students with declared disabilities, which is a rise from $6.8 \%$ in $2010-2011$ to $18.5 \%$ in $2018-2019$. To some extent, disclosure data reflects a context where students have become more aware of the benefits of declaring a disability, where disclosure is encouraged and built into registration processes, and where the categories used now are broader and more inclusive (Cooper, 2014). Students who declare a disability face different situations when attending HE (Seale et al., 2015), and research points out they historically achieve poorer academic results (Richardson, 2016). Massive open online courses (MOOCs) provide a further form of online distance education. Law et al. (2013) reported that substantial numbers of learners with accessibility needs are using open educational resources (OER) and MOOCs. However, there is limited research on how MOOCs are designed to consider accessibility and the diverse needs of their learners (Ingavélez-Guerra et al., 2020; Park et al., 2019; Sanchez-Gordon \& Luján-Mora, 2017; Zhang et al., 2020). 
This paper reports a study that investigated the perspectives of MOOC providers on accessibility. It also uncovered the perceptions of staff towards MOOC learners with accessibility needs and revealed the processes providers use to design platforms and courses and how they consider accessibility.

\section{Background and related work}

As Ingavélez-Guerra et al. (2020), Sanchez-Gordon and Luján-Mora (2017) and Zhang et al. (2020) reported in their literature reviews, research on accessibility of MOOCs is limited. There exists a lack of understanding of the diverse needs of MOOC learners and how to apply accessibility standards. Within MOOC accessibility studies, the trend is towards technical reports where accessibility is evaluated using human-computer interaction techniques and the Web content accessibility guidelines (WCAG) (World Wide Web Consortium, 2021), which is the de facto standard of web accessibility. In these studies, expert evaluation dominates, where one or more accessibility experts apply certain heuristic criteria using automatic tools (Akgul, 2018; Martin et al., 2016). Other authors have complemented the heuristic evaluation with user participation in the assessment process: vision-impaired users (Królak et al., 2017; Park et al., 2019) or the elderly (Bong \& Chen, 2016). Most studies evaluate one MOOC and its corresponding platform and tend to involve vision-impaired learners as participants. For a better understanding of the accessibility barriers in MOOCs, studies should cover a combination of different accessibility evaluation methods and a broader sample of end users with accessibility needs.

Moreover, there is a lack of research on the efforts of MOOC providers towards MOOCs accessibility (Iniesto, 2020). Our analysis of the preliminary results from the first set of interviews included in this study (Phase 1) showed limited progress in producing accessible MOOCs (Iniesto et al., 2016). Very few authors provide an overview of the process of developing a MOOC, including accessibility considerations. Smith et al. (2017) aimed to explore what they named "disability pedagogy" in MOOCs, reflecting that much of the work on MOOC development and design is quite ad hoc, showing how difficult it is to get development teams working together for accessible design.

A characteristic of MOOCs, where accessibility is a key aspect, is the high degree of interaction between learners in forums (Wong et al., 2015) or in peer assessments (Gamage et al., 2021). In MOOCs, the role of the course team changes, being less prominent than it is in traditional online learning (Papathoma, 2019). Therefore, the study reported in this paper aimed to investigate the perspectives of MOOC providers on learners with accessibility needs participating in their MOOCs and how they considered those needs. The study also investigated the processes for accessibility management in individual organisations. A set of interviews was designed to elicit the perspectives of MOOC providers through the following research questions (RQ):

- RQ1. How do MOOC providers cater for learners with accessibility needs?

- RQ2. What is the current state of accessibility in MOOCs?

- RQ3. How can accessibility barriers in MOOCs be identified and addressed?

This study is part of a broader program of research that investigated the state of accessibility in MOOCs. The other studies included a survey data with learners participating in MOOCs, interviews with learners who declare a disability and an accessibility audit that involved evaluating MOOCs from major platforms (Iniesto, 2020).

\section{Methodology}

The study consisted of 26 semi-structured online and face-to-face interviews conducted both in English and Spanish with MOOC providers focused on MOOC accessibility divided in two differentiated phases and using thematic analysis. As per methodological design, names of institutions remain identifiable.

\section{Role of MOOC providers}

For the research design, we began by defining the different roles of MOOC providers. Figure 1 shows the division of different profiles of the roles encompassed by MOOC providers, which are similar to those in 
HE course production (Burgstahler, 2015). MOOC providers can be those that provide the courses, which can be any educational institution (course providers), and can be platforms with different partners, such as FutureLearn or edX, or in-house platforms, such as the case of UNED Abierta (platform providers). These profiles also include an external group added for this study: MOOC researchers. This group complements the information from MOOC providers.

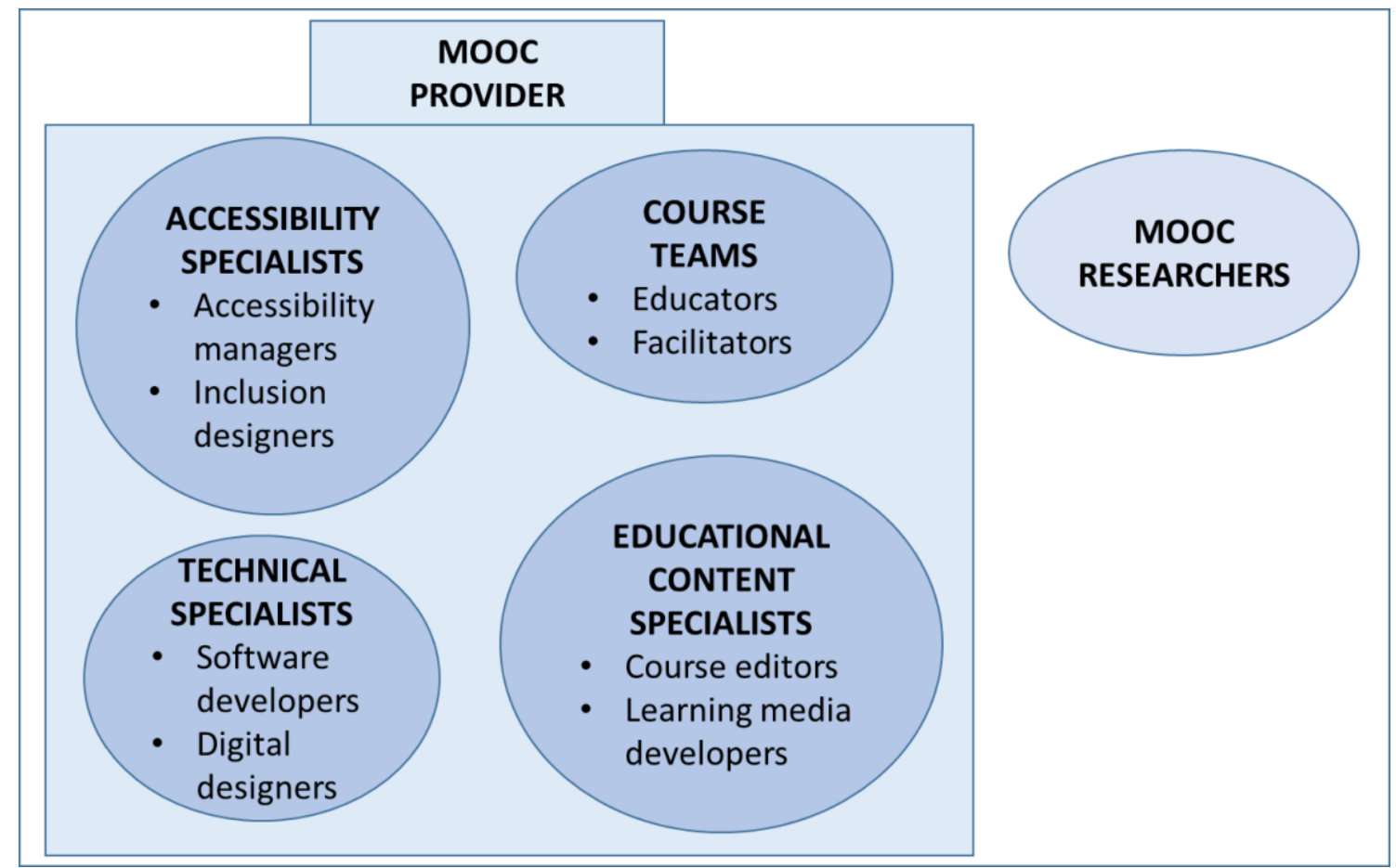

Figure 1. MOOC providers and researchers

The definitions of the roles in Figure 1 are:

- Accessibility specialists. Accessibility specialists may be involved in platform development or can help to produce the educational materials in MOOCs, being responsible for the accessibility. This role includes accessibility managers and inclusion designers (Slater et al., 2015).

- Technical specialists. This group includes those who work in developing the software for the platform; for example, software developers who work in the programming aspects and digital designers who design the visual elements (Coates et al., 2005).

- Course teams. Course teams design the educational resources of the MOOCs. This group includes educators and those who facilitate the discussion when the MOOC is being run (Hernández et al., 2016).

- Educational content specialists. Educational content specialists produce digital materials and support the course teams. This group includes course editors and learning media developers (Hernández et al., 2016).

- MOOC researchers. This group is not involved with the design and development of MOOCs. Instead, they include researchers with interest in MOOC accessibility.

Baturay's (2015) review of MOOCs around the world and the annual MOOC lists made by Class Central (Shah, 2016, 2017) were helpful in helping us to identify MOOC providers who could possibly be contacted. For clarity, the names and definitions used for the analysis are based on definitions from FutureLearn's (n.d.b) learning design resources. These can include articles, discussions (forums), videos, audios, peer review, quizzes, tests, and exercises. 


\section{Design of the interviews}

An interview study with 26 participants was conducted to understand the perspectives of MOOC providers on accessibility. Interviewees had different roles, as described in the previous section, allowing us to capture diverse perspectives and enrich the study (Bloor \& Wood, 2006). The study had two phases: Phase 1 was designed to get an understanding of MOOC providers' opinions to identify missing perspectives after its data analysis (Iniesto et al., 2016). Phase 2 was designed to fill the identified gaps and further answer the research questions (Tuckett, 2005).

Before the recruiting process, a pilot run of the interview protocols was conducted to validate the prompting and order of the questions (Castillo-Montoya, 2016). Ethical approval for the research was granted by The Open University's Human Research Ethics Committee (HREC/2017/2451/Iniesto). The whole process took place between January 2016 and April 2017. The interview protocol focused on three main topics corresponding to the research questions; each interview lasted for approximately 45 minutes:

- Data availability and knowledge about learners with accessibility needs (RQ1): The MOOC providers' understanding of learners with accessibility needs taking part in MOOCs, how they handle this information, and the way they consider the accessibility needs in their tasks. (10 minutes)

- How MOOC providers deal with accessibility (RQ2): The current state of accessibility and internal processes regarding accessibility. (15 minutes)

- MOOCs and adaptation (RQ3): The processes for addressing accessibility barriers, so that educational resources and the platform are adapted to learners' accessibility needs. (10 minutes)

In addition, specific questions were designed for each participant based on their profile; for example, questions related to educational resources for the course teams and questions related to software development for the technical specialists.

Two approaches were carried out to conduct the interviews: face-to-face interviews and synchronous online interviews. Face-to-face interviews took place in the working environment of the interviewee. At the start of each interview, participants were given a copy of the project summary sheet and consent form. Synchronous online interviews were conducted with a wider range of interviewees to facilitate their participation in the research as they were located in different countries (Janghorban et al., 2014). Online participants were provided with the same information as the face-to-face interviewees by emailing all the information before the interview. Online interviews were carried out using Skype. The consent form stated that only personal information would be anonymised, and the names of institutions and platforms could remain identifiable. Interviews were conducted in English or Spanish. Although this approach added effort to the transcription and analysis, it would help the interviewees feel more confident and secure as there was more potential to speak in a language they felt most comfortable with (Duffy et al., 2005).

\section{Sample}

For the selection of participants, the main platform providers were considered alongside MOOC researchers from the literature (Sanchez-Gordon \& Luján-Mora, 2017), and a list of MOOC providers who could participate in this study was developed. Following Sapsford and Jupp (2006), a quota sampling approach was used, being a non-probability sampling method that divides the population into non-overlapping profiles. In all, 42 providers were selected from the profiles defined. Participants were contacted by email; the acceptance response rate was high $(66.6 \%)$. From those contacted, five declined the invitation, two of those offering an alternative person within their organisation to be interviewed. Nine people did not reply to the invitation; two agreed, although in the end, the interview did not take place. This left 26 participants.

Balanced coverage of the various profiles was achieved, with a lower representation of technical specialists and educational content specialists: eight MOOC researchers (30.76\%), six course team members (23.07\%), six accessibility specialists, three technical specialists $(11.53 \%)$ and three educational content specialists (Table 1). The accessibility specialists include examples of two platform providers (FutureLearn and edX), two in-house providers (UNED Abierta and Telescopio) and one international project (Elearning, Communication and Open-data: Massive Mobile, Ubiquitous and Open Learning) (Osuna-Acedo 
et al., 2017). The sample was represented by course team members from several MOOC topics, including three of them on accessibility. The technical specialists comprised two in-house providers (UNED Abierta and iMOOC) and one platform provider (FutureLearn). The sample included three MOOC researchers with expertise in accessibility; other topics covered were learning analytics, open education, self-directed learning and universal design for learning.

This study was designed in two phases. The first phase (Phase 1) consisted of 12 interviews, while the second (Phase 2) had 14 interviews. Each phase included four MOOC researchers; while Phase 1 had a higher prevalence of technical specialists (three), Phase 2 included six course team members and three educational content specialists. A total of 10 universities and two research centres (Inclusive Design Research Centre and Center for Applied Special Technology) were represented in the sample. The languages used to participate in the interview were English (13), Spanish (9) and English as a Second Language (4). In all, 14 interviews were carried out online.

Table 1

Sample by organisation, profile, platform provider, interview type and phase

\begin{tabular}{|c|c|c|c|c|c|}
\hline ID & Organisation & Profile & $\begin{array}{l}\text { Platform } \\
\text { provider }\end{array}$ & Interview & Phase \\
\hline AS1 & FutureLearn & Accessibility specialist & FutureLearn & $\mathrm{F} 2 \mathrm{~F}$ & 1 \\
\hline AS2 & Galileo University & Accessibility specialist & Telescopio & Online & 1 \\
\hline AS3 & $\mathrm{ECO}$ & Accessibility specialist & Several & Online & 1 \\
\hline AS4 & $\begin{array}{l}\text { National Distance Education } \\
\text { University }\end{array}$ & Accessibility specialist & $\begin{array}{l}\text { UNED } \\
\text { Abierta } \\
\end{array}$ & Online & 1 \\
\hline AS5 & edX & Accessibility specialist & edX & Online & 1 \\
\hline AS6 & $\begin{array}{l}\text { Inclusive Design Research Centre, } \\
\text { Ontario College of Art \& Design } \\
\text { University }\end{array}$ & Inclusion designer & None & $\mathrm{F} 2 \mathrm{~F}$ & 2 \\
\hline TS1 & FutureLearn & Software developer & FutureLearn & F2F & 1 \\
\hline TS2 & Universidade Aberta & Software developer & iMOOC & Online & 1 \\
\hline TS3 & $\begin{array}{l}\text { National Distance Education } \\
\text { University }\end{array}$ & Software developer & $\begin{array}{l}\text { UNED } \\
\text { Abierta } \\
\end{array}$ & Online & 1 \\
\hline CT1 & Colorado Community College & Educator & Canvas & Online & 2 \\
\hline CT2 & SUNY Empire State College & Educator & Canvas & Online & 2 \\
\hline CT3 & $\begin{array}{l}\text { National Distance Education } \\
\text { University }\end{array}$ & Educator & $\begin{array}{l}\text { UNED } \\
\text { Abierta }\end{array}$ & Online & 2 \\
\hline CT4 & The Open University & Educator & FutureLearn & F2F & 2 \\
\hline CT5 & The Open University & Educator & FutureLearn & $\mathrm{F} 2 \mathrm{~F}$ & 2 \\
\hline CT6 & The Open University & Educator & edX & $\mathrm{F} 2 \mathrm{~F}$ & 2 \\
\hline ECS1 & The Open University & $\begin{array}{l}\text { Learning media } \\
\text { developer }\end{array}$ & FutureLearn & F2F & 2 \\
\hline ECS2 & The Open University & Course editor & None & F2F & 2 \\
\hline ECS3 & Freelance & Course editor & FutureLearn & F2F & 2 \\
\hline MR1 & $\begin{array}{l}\text { National Distance Education } \\
\text { University }\end{array}$ & Accessibility researcher & $\begin{array}{l}\text { UNED } \\
\text { Abierta }\end{array}$ & $\mathrm{F} 2 \mathrm{~F}$ & 1 \\
\hline MR2 & $\begin{array}{l}\text { National Distance Education } \\
\text { University }\end{array}$ & Accessibility researcher & Several & $\mathrm{F} 2 \mathrm{~F}$ & 1 \\
\hline MR3 & Polytechnic University of Madrid & Quality researcher & None & Online & 1 \\
\hline MR4 & National Polytechnic School & Accessibility researcher & None & Online & 1 \\
\hline MR5 & The Open University & $\begin{array}{l}\text { Self-directed learning } \\
\text { researcher }\end{array}$ & FutureLearn & Online & 2 \\
\hline MR6 & University of Leeds & $\begin{array}{l}\text { Learning analytics } \\
\text { researcher }\end{array}$ & FutureLearn & Online & 2 \\
\hline MR7 & $\begin{array}{l}\text { Fontys University of Applied } \\
\text { Sciences }\end{array}$ & $\begin{array}{l}\text { Open education } \\
\text { researcher }\end{array}$ & None & Online & 2 \\
\hline MR8 & $\begin{array}{l}\text { Center for Applied Special } \\
\text { Technology }\end{array}$ & $\begin{array}{l}\text { Universal design for } \\
\text { learning researcher }\end{array}$ & None & $\mathrm{F} 2 \mathrm{~F}$ & 2 \\
\hline
\end{tabular}

Note. F2F - face-to-face. 


\section{Data analysis and validation}

We produced complete English language transcripts from the verbal data from the recorded audiointerviews (Lapadat \& Lindsay, 1999) as the team included both native English and Spanish speakers. There are challenges associated with foreign language transcription (MacLean et al., 2004), but efforts were made to keep the terminology consistent; for example, preferring the use of learners over students, people over users. For the quotes selected and presented in the Results section, an intelligent verbatim transcription approach has been used; this means we have performed light editing to correct sentences, grammar and irrelevant words. Following MacLean et al. (2004), an edited transcription to use British English and identity-first language was adopted to homogenise the quotes.

Thematic analysis was applied to the exploratory interviews in this research area of MOOC accessibility, where there has not been significant previous qualitative research (Lapadat, 2009). Heterogeneity of samples further reinforced the choice of the thematic analysis method for analysis of the interview data. The 6-phase methodology of thematic analysis by Braun and Clarke (2006) has been applied three times, as shown in Table 2. The process had two levels of depth, using themes and sub-themes. The themes and sub-themes represent an interpretative level approach (i.e., not requiring literal words to appear in the transcripts) (Boyatzis, 1998). For the analysis, we have combined manual techniques using printed copies and computer-assisted software such as NVivo.

Table 2

Thematic analysis iterations

\begin{tabular}{llc}
\hline Phase & Iterations \\
\hline 1. & Familiarising with the data & 2 \\
2. & Generating initial codes & 3 \\
3. & Searching for themes & 3 \\
4. & Reviewing themes & 3 \\
5. Defining and naming themes & 3 \\
6. & Producing the report & 1 \\
\hline
\end{tabular}

The three iterations were as follows:

- The first iteration. This iteration consisted of the data from the 12 interviews from Phase 1. An inductive approach of qualitative data analysis approach was used. This allowed a better understanding of MOOC providers' opinions and helped to identify missing data required to answer the research questions. The analysis generated five themes and 17 sub-themes.

- The second iteration. This interaction added the data from the 14 interviews included in Phase 2 , including missing profiles in the previous iteration. The same inductive approach was used to develop a total of six themes with 32 sub-themes. This iteration allowed a profound understanding of the data set, considering the diversity of profiles interviewed. However, the number of themes and sub-themes that were produced from this iteration were too broad and they did not help to answer the research questions.

- The third iteration. This iteration was carried out with a deductive nature. The final iteration aimed to answer the research questions proposed for this study, and themes that did not help to answer the questions were removed. An effort to merge the themes and sub-themes and refine their semantics was taken, resulting in four themes and 13 sub-themes.

Two of us validated the semantics of the final iteration conducting an inter-reliability process. This involved 105 quotes (18.48\% of the data set) and three possible answers between randomised sub-themes. The agreement was substantial, with a Cohen's kappa of 0.71 (Table 3). The coverage is as per percentage provided by Strijbos et al. (2006) (between $10 \%$ and 15\%). 
Table 3

Cohen's kappa for the final iteration validation

\begin{tabular}{lc}
\hline & Value \\
\hline Relative observed agreement & $85 / 105$ \\
Hypothetical probability & $1 / 3$ \\
Cohen's kappa & 0.71 \\
\hline
\end{tabular}

\section{Results}

Figure 2 represents the thematic map of the third iteration including the counts of themes and sub-themes. Results are broken down as per the research questions. The themes, sub-themes and example quotes from the analysed data are detailed in Tables 4, 5 and 6 in the following section.

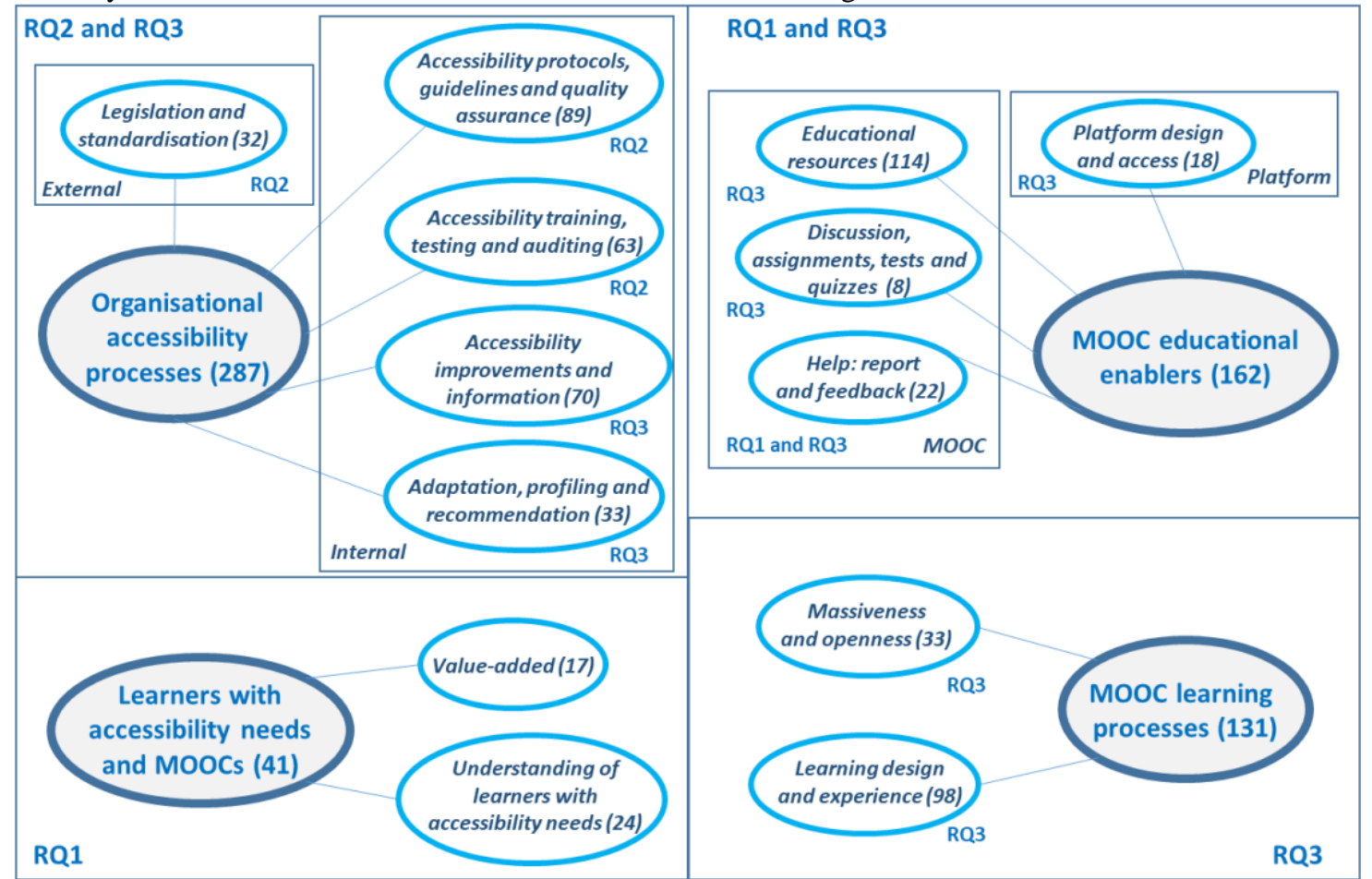

Figure 1. Thematic map representing the themes and sub-themes at the final iteration

\section{How MOOC providers cater for learners with accessibility needs}

Providers agree that MOOCs can be helpful for learners with accessibility needs, for example, for undertaking continuing professional development, improving career and study opportunities through acquiring new competencies and exploring options for the certifications that MOOCs offer. MOOCs allow social integration by facilitating learners with accessibility needs to socialise with other learners. MOOCs enable learners with accessibility needs to work in their environment (place) and at their rhythm or pace, facilitating self-regulated learning (Table 4). The openness and low cost of MOOCs are value-added features for those learners who face socio-economic disadvantages. 
Table 4

How MOOC providers cater for learners with accessibility needs

\begin{tabular}{|c|c|c|}
\hline Theme & Sub-theme & Sample quotes from the analysed data \\
\hline \multirow[t]{2}{*}{$\begin{array}{l}\text { Learners with } \\
\text { accessibility } \\
\text { needs } \\
\text { and MOOCs }\end{array}$} & Value-added & $\begin{array}{l}\text { MOOCs are attractive to disabled learners because they break down a lot of } \\
\text { the barriers. They may also face discrimination because any disability that } \\
\text { they may have is invisible, they are interested in the digital world because of } \\
\text { the availability of assistive technologies, the digital world is potentially } \\
\text { more accessible, MOOCs are more attractive to disabled learners. (AS5, } \\
\text { edX, edX) }\end{array}$ \\
\hline & $\begin{array}{l}\text { Understanding } \\
\text { of learners } \\
\text { with } \\
\text { accessibility } \\
\text { needs }\end{array}$ & $\begin{array}{l}\text { We have seen anecdotal evidence of disabled learners saying they like } \\
\text { taking the courses because it exposes them to other learners or it has the } \\
\text { social and the community elements, getting to talk to people when they } \\
\text { might be more isolated at home. (AS1, FutureLearn, FutureLearn) }\end{array}$ \\
\hline $\begin{array}{l}\text { MOOC } \\
\text { educational } \\
\text { enablers }\end{array}$ & $\begin{array}{l}\text { Help: report } \\
\text { and feedback }\end{array}$ & $\begin{array}{l}\text { We encourage our learners to help each other as well because often, the } \\
\text { learners can spot an issue quicker than a facilitator, because they are reading } \\
\text { through everything, they can see something. (CT4, Open University, } \\
\text { FutureLearn) }\end{array}$ \\
\hline
\end{tabular}

Providers are aware of some of the factors that can affect learners with accessibility needs while participating in MOOCs. One of the factors is the use of the Web; if Web accessibility standards are not applied correctly, it can create accessibility barriers. Therefore, they are conscious of the fact that legislation is driving accessibility. Their priority is to meet the standards to satisfy legal requirements; therefore, they do not think of accessibility as a service to the learner but to meet the legislative requirements.

There is a lack of understanding of the number of learners with accessibility needs engaging with MOOCs. The standard way to obtain participation information (profiles) is via surveys at the beginning or end of the MOOCs. Also, learners report accessibility barriers, either via feedback forms or using the comments feature within the online environment. In most MOOC surveys, very little demographic information is requested. In some cases, course providers show awareness of accessibility in their courses. However, when discussing with them during our empirical research, we observed that accessibility and disability in their terms are primarily linked to physical disabilities, and sometimes only to visual impairments.

\section{The current state of accessibility in MOOCs}

As reported, legislation and standards play an important role in the organisational processes of both platforms and course providers (Table 5). There are a variety of standards, but the lack of international unification creates difficulties in their application. Therefore, Web accessibility standards are not necessarily being followed, although there is an awareness of the existence of these and an intention to meet the legal requirements.

Table 5

The current state of accessibility in MOOCs

\begin{tabular}{lll}
\hline Theme & Sub-theme & Sample of quotes from analysed data \\
\hline $\begin{array}{l}\text { Organisational } \\
\text { processibility }\end{array}$ & $\begin{array}{l}\text { Legislation and } \\
\text { standardisation }\end{array}$ & $\begin{array}{l}\text { If Open edX is more accessible, these improvements will be implemented } \\
\text { in other organisations that use it, even if these organisations are in } \\
\text { countries that do not follow the legislation. (MR1, UNED, UNED } \\
\text { Abierta) }\end{array}$ \\
& $\begin{array}{l}\text { For a lot of universities that don't make an online offering this is the first } \\
\text { time that they come up against it, so there's a number of factors where } \\
\text { protocols, } \\
\text { guidelines and } \\
\text { quality assurance } \\
\text { Accessibility } \\
\text { training, testing } \\
\text { and auditing }\end{array}$ & $\begin{array}{l}\text { University, None) } \\
\text { Accessibility has to be incorporated from the beginning, when you do not } \\
\text { know anything about accessibility you can think that it is just added work, } \\
\text { work that you have to make an extra effort. (CT3, UNED, UNED } \\
\text { Abierta) }\end{array}$ \\
\hline
\end{tabular}

Platform providers are required to check accessibility during the software development of the platform and have their internal (platform-specific) accessibility protocols and guidelines. There is a lack of consistency between providers' accessibility guidelines. Course providers have varied levels of knowledge of 
accessibility while producing educational resources, and there is a diverse understanding of accessibility between organisations. Some organisations have in-house accessibility guidelines, while others use platform-specific ones. In some cases, course teams deal with accessibility, while in some other organisations, course teams are not necessarily aware of accessibility. Some platform providers develop accessibility guidelines and provide training to the course providers, but the responsibility to cater for accessibility within the course educational resources lies mostly with the course providers.

\section{How accessibility barriers in MOOCs can be identified and addressed}

With regards to the learning process, there are two factors that influence accessibility for MOOC providers: massiveness and openness (Table 6). Some opinions reflect an assumption that accessibility is increased if openness is increased, and so openness can be a route to accessibility. Massiveness can also help accessibility because of greater access to analytics, that can identify different situations of learners with accessibility needs. The learning and pedagogical designs should cater for accessibility. Providers are conscious of the fact that the quantity of material delivered each week and the schedule learners can follow influence their learning experience.

Table 6

How accessibility barriers in MOOCs can be identified and addressed

\begin{tabular}{|c|c|c|}
\hline Theme & Sub-theme & Sample of quotes from analysed data \\
\hline \multirow[t]{2}{*}{$\begin{array}{l}\text { MOOC } \\
\text { learning } \\
\text { processes }\end{array}$} & $\begin{array}{l}\text { Massiveness } \\
\text { and openness }\end{array}$ & $\begin{array}{l}\text { If you are fully engaged in that kind of rhetoric fully open, you are } \\
\text { developing content in a way that is more easily accessible genuinely. } \\
\text { Therefore, if you engage MOOCs on that level, yes, they can help to } \\
\text { encourage accessibility. (CT6, Open University, edX) }\end{array}$ \\
\hline & $\begin{array}{l}\text { Learning design and } \\
\text { experience }\end{array}$ & $\begin{array}{l}\text { We try that the courses can be studied in terms of each one's needs than } \\
\text { one online learning, you can pass to unit four without studying unit one, } \\
\text { this is one of the keys. (AS3, ECO, Several) }\end{array}$ \\
\hline \multirow[t]{2}{*}{$\begin{array}{l}\text { Organisational } \\
\text { accessibility } \\
\text { processes }\end{array}$} & $\begin{array}{l}\text { Accessibility } \\
\text { improvements and } \\
\text { information }\end{array}$ & $\begin{array}{l}\text { When putting that list together having to declare on that page how } \\
\text { accessible the MOOC is it might really bring into focus the importance } \\
\text { of accessibility and remind them to think about it is a way that impacts } \\
\text { their course. (AS1, FutureLearn, FutureLearn) }\end{array}$ \\
\hline & $\begin{array}{l}\text { Adaptation, profiling } \\
\text { and recommendation }\end{array}$ & $\begin{array}{l}\text { Where MOOCs could be powerful is to realise having a profile is the } \\
\text { first step but in fact what MOOCs can do by paying attention to what's } \\
\text { going on now is to track the changes in your profile, immediate changes. } \\
\text { (MR8, Center for Applied Special Technology, None) }\end{array}$ \\
\hline \multirow[t]{2}{*}{$\begin{array}{l}\text { MOOC } \\
\text { educational } \\
\text { enablers }\end{array}$} & $\begin{array}{l}\text { Platform design and } \\
\text { access }\end{array}$ & $\begin{array}{l}\text { We have queries from learners who want to do courses in remote parts } \\
\text { of the world where you have people that have problems to get an } \\
\text { internet connection. (TS1, FutureLearn, FutureLearn) }\end{array}$ \\
\hline & $\begin{array}{l}\text { Educational } \\
\text { resources }\end{array}$ & $\begin{array}{l}\text { Never have anything longer than a minute, and if it's absolutely } \\
\text { necessary for particular learning purposes it can go on for maybe two } \\
\text { and a half minutes. (ECS3, Freelance, FutureLearn) }\end{array}$ \\
\hline
\end{tabular}

There are several aspects to identifying and addressing accessibility barriers. It can be difficult to draw a line between the accessibility responsibilities of platform and course providers, for example, for the accessibility testing of educational resources, which have been designed by the course provider but embedded in the platform. However, course providers are the ones who have produced the resources and will have the responsibility to adapt and enhance them if accessibility barriers are found. Both platform and course providers agree on the need to develop processes to improve accessibility, by including accessibility in the early production of educational resources and platforms.

\section{Discussion}

\section{Contributions of this research}

Findings from this research show that providers perceive MOOCs to be helpful for learners with accessibility needs for continuing professional development and certification for all learners because of their openness and low cost - a benefit reported by Dennen and Bong (2017). This is a major benefit, as the number of unemployed who declare a disability in the labour market is significantly high (Powell, 2018). As Wong et al. (2015) reported, MOOCs enable learning with others and foster social learning. There is an agreement amongst providers that social interactions in MOOCs provide opportunities to 
learners with accessibility needs to socialise and to foster their self-regulated learning. This aspect is critical, considering the current shift of some MOOC providers to a less massive and more closed environment for MOOCs (Hood \& Littlejohn, 2019).

Although Smith et al. (2017) provided an overview of the process of developing MOOCs from the experiences of course teams, there is limited research for understanding MOOC accessibility development processes. MOOC providers cater for learners with accessibility needs, and they are sensitised to their needs. However, it is not known who is participating in MOOCs, as providers are not tracking the audience who are taking up their courses. The lack of information makes it difficult to design educational resources that consider different target groups and provide preferences for personalisation of the learning experience. There is a lack of data on accessibility needs in online learning, either via building profiles or during registration processes (Perryman \& de Los Arcos, 2016). The interviews in the study reported in this paper indicate that MOOCs are not an exception in the absence of accessibility data; although the potential of its use to support learners has previously been identified (Porter, 2014). The low level of commitment required to study a MOOC creates additional difficulty in capturing rich data (Littlejohn et al., 2016).

One of the main aspects identified in this study is the disparity of processes between MOOC providers. The design of MOOC platforms is determined by legislation, and that is driving accessibility, which means that learners with accessibility needs are not a priority when developing platforms and courses. Rather, the focus is on meeting the standards and legislation requirements. Even though providers are aware that technology can be an accessibility barrier, and that allowing for flexibility and personalisation in MOOCs could be a solution, not much effort is being made to meet accessibility needs (i.e., meeting legislation is not equivalent to making learning fully accessible). This perspective is supported by Daniel et al. (2015), who questioned the viability of personalisation within the MOOC business model. Providers, however, agree that it should be easier for learners to find help, report accessibility barriers, get feedback and access mechanisms to help each other. A better understanding of learners' feedback can help to support accessibility (Coughlan et al., 2017).

Other aspects that were uncovered in this study include the limited training that course teams have in MOOC development, also reported in previous research (e.g., Haavind \& Sistek-Chandler, 2015; Papathoma, 2019). Sanchez-Gordon and Luján-Mora (2016) and Sanderson et al. (2016) highlighted the use of authoring tools to create and edit accessible educational resources for MOOCs. For that purpose, adequate authoring tools need to be provided to course teams. Authoring tools should facilitate accessibility as part of the design and development of educational resources. Furthermore, they should allow the inclusion of accessibility checklists to evaluate the resource before it is delivered on the platform. Course providers invest lots of money in video production, and there is a lack of understanding that not all learners enjoy them or find them accessible, and some may prefer to read text or could only access text.

Therefore, to be able to support accessibility in MOOCs, it is important to consider the following:

- Platform design and access. The design of the MOOC platform needs to be simple and customisable; learners need to know where they are at each interaction. There is no need to add too many features, but the design should facilitate different learning paths, depending on the learners' preferences. Access should not depend on a good Internet connection; there need to be options for offline access to content.

- Course main page. Showing accessibility information at the beginning of the MOOC (presented as advice and not as a limitation to taking part in the course) can be useful to learners. The use of accessibility profiling options in MOOCs would support learners by providing the resources which meet their needs. That personalisation may allow for recommending MOOCs.

- Educational resources. Educational resources need to cater for language and cultural barriers and should include alternative formats. The length of videos and clarity of the language used in them should be considered for accessibility. Therefore, the videos should be audio-described, provide accurate captions and transcripts and, if possible, include sign language.

- Discussion, assignments, tests and quizzes. Assignments, tests and quizzes can add to accessibility barriers and increase the dropout rate. Discussions in forums should be designed in a way that they are easy to follow, and assignments and quizzes should be optional and provide feedback and alternative ways of gaining the knowledge. 
- Help: Report and feedback. Platform providers should ensure that there are options for help to report barriers, for example, providing help buttons that are always available, instead of learners having to use the community space of forums to report their accessibility barriers and publicly sharing their constraints to learning.

\section{Limitations and directions for future research}

One of the limitations in this study is that the profiles included are professionals who work in areas of software development and educational content. As Libby and Rennekamp (2012) reported, it is natural to expect self-serving bias in how MOOC providers report their management of accessibility. Another limitation is that there are some missing voices in this sample. For example, during the recruitment process, contact was attempted with other major platforms, but either they did not respond or they declined requests for participation. In addition, providers with a significant number of learners outside the English and Spanish-speaking context, such as Asian platforms (in China and India) and European platforms (in France and Germany), were not included in the participant set. Their involvement would have added a wider global perspective to the research investigations. Furthermore, facilitators who moderate forums, address queries and have a day-to-day insight into the dynamics of collaboration in MOOCs are also not included (Beaven et al., 2014).

There is a need to develop processes to improve accessibility by including accessibility in the early production of educational resources and platforms (Ingavélez-Guerra et al., 2020; Zhang et al., 2020). To achieve this objective, it is important to elicit the perspectives of MOOC stakeholder groups. The research program, of which this study is part, includes studies with learners and an application of heuristic evaluations for auditing MOOCs (Iniesto, 2020). As indicated by MOOC providers, obtaining feedback from learners enables the platform to be adapted and the design of educational resources to meet learners' accessibility needs (Iniesto et al, 2017). The lack of accessibility data from learners in MOOC platforms should be addressed by considering the role of MOOC recommender systems (Iniesto \& Rodrigo, 2019) and that of learning analytics (Cooper et al., 2016). As discussed with MOOC providers, future research should involve developing accessibility profiling standards and their practical application in open education (Navarrete \& Luján-Mora, 2018) and in learning at scale (Papathoma et al., 2020). Those aspects, if addressed, will allow personalisation and possibilities for offering advice and guidance for learners (Iniesto et al., 2021).

\section{Conclusions}

This study explored MOOC provider perspectives on accessibility, enabling the development of a deeper understanding of the accessibility of internal processes in the design of platforms and educational resources. Although the research reported in this paper shows that there are inherent challenges in accessible MOOC production, they are inherent to any open online learning course production in an agile development methodology (Zhang et al., 2020).

As a general approach, online course providers should seek a better understanding of their learners and their needs. Online course development processes need to be reviewed from the design stages to produce accessible content, and the focus should change from meeting legislative requirements to meeting learners' needs. International legislation is pushing unification of standards forward; for example, FutureLearn now has to meet WCAG (and inform learners if it is not the case) since it is a platform provider used by course providers who are bound to follow the public sector regulations (FutureLearn., n.d.a). Therefore, there seems to be increasing parity of expectations of WCAG compliance, even if there is no immediate legal requirement for it. To have an impact creating more accessible online courses, it is necessary to put in place processes to identify accessibility barriers, to strengthen mechanisms that involve the participation of learners in course design and to facilitate agile responses in addressing barriers. 


\section{Acknowledgements}

This research was supported by a Leverhulme Trust Doctoral Scholarship in Open World Learning based at the Institute of Educational Technology at The Open University. Francisco thanks the Global OER Graduate Network, which is supported by the William and Flora Hewlett Foundation. We are grateful for the time and dedication of the participants in this study.

\section{References}

Akgul, Y. (2018). Web accessibility of MOOCs for elderly students: The case of Turkey. Journal of Life Economics, 5(4), 141-150. https://doi.org/10.15637/jlecon.266

Baturay, M. H. (2015). An overview of the world of MOOCs. Procedia - Social and Behavioral Sciences, 174, 427-433. https://doi.org/10.1016/j.sbspro.2015.01.685

Beaven, T., Hauck, M., Comas-Quinn, A., Lewis, T., \& de los Arcos, B. (2014). MOOCs: Striking the right balance between facilitation and self-determination. MERLOT Journal of Online Learning and Teaching, 10(1), 31-43. https://jolt.merlot.org/Vol10_No1.htm

Bloor, C. M., \& Wood, F. (2006). Keywords in qualitative methods vignettes: A vocabulary of research concepts. Sage. https://doi.org/10.4135/9781849209403

Bong, W. K., \& Chen, W. (2016). How accessible are MOOCs to the elderly? In K. Miesenberger, C. Bühler, \& P. Penaz (Eds.), Lecture notes in computer science: Vol. 9758. International conference on computers helping people with special needs (pp. 437-444). Springer. https://doi.org/10.1007/978-3319-41264-1_60

Boyatzis, R. E. (1998). Transforming qualitative information: Thematic analysis and code development. Sage.

Braun, V., \& Clarke, V. (2006). Using thematic analysis in psychology. Qualitative Research in Psychology, 3(2), 77-101. https://doi.org/10.1191/1478088706qp063oa

Burgstahler, S. (Ed.). (2015). Universal design in higher education: From principles to practice (2nd ed.). Harvard Education Press.

Castillo-Montoya, M. (2016). Preparing for interview research: The interview protocol refinement framework. The Qualitative Report, 21(5), 811-831. https://doi.org/10.46743/2160-3715/2016.2337

Coates, H., James, R., \& Baldwin, G. (2005). A critical examination of the effects of learning management systems on university teaching and learning. Tertiary Education and Management, 11, 19-36. https://doi.org/10.1007/s11233-004-3567-9

Cooper, M. (2014). Meeting the needs of disabled students in online distance education-an institutional case study from The Open University, UK. Distance Education in China, 2014(12), 18-27.

Cooper, M., Ferguson, R., \& Wolff, A. (2016). What can analytics contribute to accessibility in e-learning systems and to disabled students' learning? In D. Gašević, \& G. Lynch (Eds.), Proceedings of the Sixth International Conference on Learning Analytics \& Knowledge (pp. 99-103). Association for Computing Machinery. https://doi.org/10.1145/2883851.2883946

Coughlan, T., Rodriguez-Ascaso, A., Iniesto, F., \& Jelfs, A. (2016). OLA! A scenario-based approach to enhance open learning through accessibility. In K. Miesenberger, C. Bühler, \& P. Penaz (Eds.), Lecture notes in computer science: Vol. 9758. International conference on computers helping people with special needs (pp. 445-452). Springer. https://doi.org/10.1007/978-3-319-41264-1_61

Coughlan, T., Ullmann, T. D., \& Lister, K. (2017). Understanding accessibility as a process through the analysis of feedback from disabled Students. In C. Bailey \& V. Gkatzidou (Eds.), Proceedings of the 14th Web for All Conference on The Future of Accessible Work (pp. 1-10). Association for Computing Machinery. https://doi.org/10.1145/3058555.3058561

Daniel, J., Cano, E. V., \& Cervera, M. G. (2015). The future of MOOCs: Adaptive learning or business model? International Journal of Educational Technology in Higher Education, 12(1), 64-73. https://doi.org/10.7238/rusc.v12i1.2475

Dennen, V. P., \& Bong, J. (2017). Reframing MOOCs in higher education: Exploring professional development options. In R. Bennett \& M. Kent (Eds.), Massive open online courses and higher education: What went right, what went wrong and where to next? (pp. 151-167). Routledge. https://doi.org/10.4324/9781315594248

Duffy, B., Smith, K., Terhanian, G., \& Bremer, J. (2005). Comparing data from online and face-to-face surveys. International Journal of Market Research, 47(6), 615-639.

https://doi.org/10.1177/147078530504700602 
FutureLearn. (n.d.a). Accessibility and inclusion policy. https://www.futurelearn.com/info/terms/accessibility-policy

FutureLearn. (n.d.b). Learning on FutureLearn: Using FutureLearn. https://www.futurelearn.com/usingfuturelearn

Gamage, D., Staubitz, T., \& Whiting, M. (2021). Peer assessment in MOOCs: Systematic literature review. Distance Education, 42(2), 1-22. https://doi.org/10.1080/01587919.2021.1911626

Haavind, S., \& Sistek-Chandler, C. (2015). The emergent role of the MOOC instructor: A qualitative study of trends toward improving future practice. International Journal on E-Learning, 14(3), 331350. https://www.learntechlib.org/p/150663/

Hernández, P. G., Barrera, A. G., \& López, C. M. (Eds.). (2016). La Cultura de Los MOOCs: Para La Innovacion En Educación Superior Desde Contextos Iberoamericanos [The culture of MOOCs: For innovation in higher education from Ibero-American contexts]. Editorial Sintesis.

Higher Education Statistics Agency. (2021). Widening participation summary: UK performance indicators. https://www.hesa.ac.uk/data-and-analysis/performance-indicators/widening-participationsummary

Hood, N., \& Littlejohn, A. (2019). Disruptive democratisers? The complexities and incongruities of scale, diversity and personalisation in MOOCs. In E. Ossiannilsson (Ed.), Ubiquitous inclusive learning in a digital era (pp. 1-28). IGI Global. https://doi.org/10.4018/978-1-5225-6292-4.ch001

Ingavélez-Guerra, P., Otón-Tortosa, S., Teixeira, A., Robles-Bykbaev, V., \& Pérez-Muñoz, A. (2020). Exploring the impact of accessibility in MOOC and OER: A multivocal literature review. In Enhancing the Human Experience of Learning with Technology: New challenges for research in digital, open, distance \& networked education - Proceedings of the European Distance and Elearning Network Conference (pp. 95-104). EDEN. https://doi.org/10.38069/edenconf-2020-rw-0011

Iniesto, F. (2020). An Investigation into the accessibility of massive open online courses (MOOCs) [Doctoral dissertation, The Open University]. Open Research Online. https://doi.org/10.21954/ou.ro.0001117a

Iniesto, F., Coughlan, T., \& Lister, K. (2021). Implementing an accessible conversational user interface: applying feedback from university students and disability support advisors. In S. Rodriguez Vazquez \& T. Drake (Eds.), Proceedings of the 18th International Web for All Conference (pp. 1-5).

Association for Computing Machinery. https://doi.org/10.1145/3430263.3452431

Iniesto, F., McAndrew, P., Minocha, S., \& Coughlan, T. (2016). Accessibility of MOOCs: Understanding the provider perspective. Journal of Interactive Media in Education, 2016 (1). http://doi.org/10.5334/jime.430

Iniesto, F., McAndrew, P., Minocha, S., \& Coughlan, T. (2017). An investigation into the perspectives of providers and learners on MOOC accessibility. In J.M Dodero, M. Soledad Ibarra Sáiz, \& I. Ruiz Rube (Eds.), Proceedings of the 5th International Conference on Technological Ecosystems for Enhancing Multiculturality (pp. 1-8). Association for Computing Machinery. https://doi.org/10.1145/3144826.3145442

Iniesto, F., \& Rodrigo, C. (2019). YourMOOC4all: A recommender system for MOOCs based on collaborative filtering implementing UDL. In M. Scheffel, J. Broisin, V. Pammer-Schindler, A. Ioannou, \& J. Schneider (Eds.), Lecture notes in computer science: Vol. 11722. European conference on technology enhanced learning (pp. 746-750). Springer. https://doi.org/10.1007/978-3030-29736-7_80

Janghorban, R., Roudsari, R. L., \& Taghipour, A. (2014). Skype interviewing: The new generation of online synchronous interview in qualitative research. International Journal of Qualitative Studies on Health and Well-Being, 9(1), Article 24152. https://doi.org/10.3402/qhw.v9.24152

Królak, A., Chen, W., Sanderson, N. C., \& Kessel, S. (2017). The Accessibility of MOOCs for Blind Learners. In A. Hurst (Ed.), Proceedings of the 19th International ACM SIGACCESS Conference on Computers and Accessibility (pp. 401-402). Association for Computing Machinery. https://doi.org/10.1145/3132525.3134796

Lapadat, J. (2009). Thematic Analysis. In A. J. Mills, G. Durepos, \& E. Wiebe (Eds.), Encyclopedia of case study research: L-Z; index (Vol. 1). Sage. https://doi.org/10.4135/9781412957397

Lapadat, J. C., \& Lindsay, A. C. (1999). Transcription in research and practice: From standardisation of technique to interpretive positionings. Qualitative Inquiry, 5(1), 64-86. https://doi.org/10.1177/107780049900500104

Law, P., Perryman, L.-A., \& Law, A. (2013). Open educational resources for all? Comparing user motivations and characteristics across The Open University's iTunes U channel and OpenLearn platform. In J. Carpentier, P. Boiron, \& M. van der Leegte (Eds.), Proceedings of the Open and 
Flexible Higher Education Conference (pp. 204-219). European Association of Distance Teaching Universities.

Libby, R., \& Rennekamp, K. (2012). Self-serving attribution bias, overconfidence, and the issuance of management forecasts. Journal of Accounting Research, 50(1), 197-231. https://doi.org/10.1111/j.1475-679X.2011.00430.x

Littlejohn, A., Hood, N., Milligan, C., \& Mustain, P. (2016). Learning in MOOCs: Motivations and selfregulated learning in MOOCs. The Internet and Higher Education, 29, 40-48. https://doi.org/10.1016/j.iheduc.2015.12.003

MacLean, L. M., Meyer, M., \& Estable, A. (2004). Improving accuracy of transcripts in qualitative research. Qualitative Health Research, 14(1), 113-123. https://doi.org/10.1177/1049732303259804

Martin, J. L., Amado-Salvatierra, H. R., \& Hilera, J. R. (2016). MOOCs for all: Evaluating the accessibility of top MOOC platforms. International Journal of Engineering Education, 32(5), 22742283. https://www.ijee.ie/contents/c320516B.html

Moriña, A. (2017). 'We aren't heroes, we're survivors': Higher education as an opportunity for students with disabilities to reinvent an identity. Journal of Further and Higher Education, 41(2), 215-226. https://doi.org/10.1080/0309877X.2015.1070402

Navarrete, R., \& Luján-Mora, S. (2018). Bridging the accessibility gap in open educational resources. Universal Access in the Information Society, 17(4), 755-774. https://doi.org/10.1007/s10209-017$\underline{0529-9}$

Osuna-Acedo, S., Gil Quintana, J., \& Cantillo Valero, C. (2017). Open, mobile and collaborative educational experience. Case study: The European ECO project. Journal of Universal Computer Science, 23(12), 1215-1237. http://jucs.org/jucs_23_12/open_mobile_and_collaborative/jucs_23_12_1215_1237_acedo.pdf

Papathoma, T. (2019). MOOC educators: Who they are and how they learn [Doctoral dissertation, The Open University]. Open Research Online. https://doi.org/10.21954/ou.ro.0000e7a6

Papathoma, T., Ferguson, R., Iniesto, F., Rets, I., Vogiatzis, D., \& Murphy, V. (2020). Guidance on how learning at scale can be made more accessible. In D. Joyner (Ed.), Proceedings of the Seventh ACM Conference on Learning @ Scale (pp. 289-292). Association for Computing Machinery https://doi.org/10.1145/3386527.3406730

Park, K., So, H.-J., \& Cha, H. (2019). Digital equity and accessible MOOCs: Accessibility evaluations of mobile MOOCs for learners with visual impairments. Australasian Journal of Educational Technology, 35(6), 48-63. https://doi.org/10.14742/ajet.5521

Perryman, L.-A., \& de los Arcos, B. (2016, April 19-20). Meeting the needs of disabled learners through OER and OEP: Insights from the OE Research Hub dataset [Paper presentation]. OER16: Open Culture, Edinburgh, United Kingdom. https://oer16.oerconf.org/sessions/meeting-the-needs-ofdisabled-learners-through-oer-and-oep-insights-from-the-oe-research-hub-dataset-1089/

Porter, J. (2014). Understanding and responding to the experience of disability. Routledge. https://doi.org/10.4324/9781315763316

Powell, A. (2018). People with disabilities in employment. (No. 7540). House of Commons Library. https://commonslibrary.parliament.uk/research-briefings/cbp-7540/

Richardson, J. T. (2016). Face-to-face versus online tutorial support in distance education: Preference, performance, and pass rates in students with disabilities. Journal of Postsecondary Education and Disability, 29(1), 83-90. http://www.aheadarchive.org/uploads/publications/JPED/JPED29_1files/JPED29_1.pdf

Sanchez-Gordon, S., \& Luján-Mora, S. (2016). How could MOOCs become accessible? The case of edX and the future of inclusive online learning. Journal of Universal Computer Science, 22, 55-81. http://jucs.org/jucs_22_1/how_could_moocs_become/jucs_22_01_0055_0081_gordon.pdf

Sanchez-Gordon, S., \& Luján-Mora, S. (2017). Research challenges in accessible MOOCs: A systematic literature review 2008-2016. Universal Access in the Information Society, 1-15. https://doi.org/10.1007/s10209-017-0531-2

Sanderson, N. C., Chen, W., Bong, W. K., \& Kessel, S. (2016). The accessibility of MOOC platforms from instructors' perspective. In M. Antona \& C. Stephanidis (Eds.), Lecture notes in computer science: Vol. 9739. International conference on universal access in human-computer interaction (pp. 124-134). Springer. https://doi.org/10.1007/978-3-319-40238-3_13

Sapsford, R., \& Jupp, V. (2006). Data collection and analysis. Sage. https://doi.org/10.4135/9781849208802

Seale, J., Georgeson, J., Mamas, C., \& Swain, J. (2015). Not the right kind of 'digital capital'? An examination of the complex relationship between disabled students, their technologies and higher 
education institutions. Computers \& Education, 82, 118-128.

https://doi.org/10.1016/j.compedu.2014.11.007

Shah, D. (2016, December 25). By the numbers: MOOCS in 2016. The Report. https://www.classcentral.com/report/mooc-stats-2016/

Shah, D. (2018, January 18). By the numbers: MOOCS in 2017. The Report. https://www.classcentral.com/report/mooc-stats-2017/

Slater, R., Pearson, V. K., Warren, J. P., \& Forbes, T. (2015). Institutional change for improving accessibility in the design and delivery of distance learning: The role of faculty accessibility specialists at The Open University. Open Learning: The Journal of Open, Distance and e-Learning, 30(1), 6-20. https://doi.org/10.1080/02680513.2015.1013528

Smith, L., Dowse, L., Soldatic, K., \& Kent, M. (2017). Developing a MOOC: factoring in disability. In R. Bennett \& M. Kent (Eds.), Massive open online courses and higher education: What went right, what went wrong and where to next? (pp. 123-134). Routledge. https://doi.org/10.4324/9781315594248

Strijbos, J.-W., Martens, R. L., Prins, F. J., \& Jochems, W. M. (2006). Content analysis: What are they talking about? Computers \& Education, 46(1), 29-48. https://doi.org/10.1016/j.compedu.2005.04.002

The Open University. (2019). Facts and figures 2019/2020.

https://www.open.ac.uk/about/main/sites/www.open.ac.uk.about.main/files/files/Facts-and-Figures2019-20.pdf

Tuckett, A. G. (2005). Applying thematic analysis theory to practice: A researcher's experience. Contemporary Nurse, 19(1-2), 75-87. https://doi.org/10.5172/conu.19.1-2.75

Wong, J.-S., Pursel, B., Divinsky, A., \& Jansen, B. J. (2015). An analysis of MOOC discussion forum interactions from the most active users. In N. Agarwal, K. Xu, \& N. Osgood (Eds.), Lecture notes in computer science: Vol. 9021. International conference on social computing, behavioral-cultural modeling, and prediction (pp. 452-457). Springer. https://doi.org/10.1007/978-3-319-16268-3 58

World Wide Web Consortium. (2021). Web content accessibility guidelines (WCAG) overview. https://www.w3.org/WAI/standards-guidelines/wcag/

Zhang, X., Tlili, A., Nascimbeni, F., Burgos, D., Huang, R., Chang, T. W., Jemni, M., \& Khribi, M. K. (2020). Accessibility within open educational resources and practices for disabled learners: A systematic literature review. Smart Learning Environments, 7, Article 1. https://doi.org/10.1186/s40561-019-0113-2

Corresponding author: Francisco Iniesto, francisco.iniesto@open.ac.uk

Copyright: Articles published in the Australasian Journal of Educational Technology (AJET) are available under Creative Commons Attribution Non-Commercial No Derivatives Licence (CC BY-NC-ND 4.0). Authors retain copyright in their work and grant AJET right of first publication under CC BY-NC-ND 4.0.

Please cite as: Iniesto, F., McAndrew, P., Minocha, S., \& Coughlan, T. (2022). A qualitative study to understand the perspectives of MOOC providers on accessibility. Australasian Journal of Educational Technology, 38(1), 87-101. https://doi.org/10.14742/ajet.6610 